\title{
Pengembangan Perangkat Pembelajaran Matematika BERBASIS DISCOVERY LEARNING UNTUK MENINGKATKAN KEMAMPUAN PEMECAHAN MASALAH SISWA KELAS VIII SMP
}

\section{DEVEloping MATHEMATICAL LEARNING DEVICE BASED ON DiSCOVERY LEARNING TO INCREASE Problem SOLVING SKILl STUdENTS Class VIII SMP}

\author{
Rahmiati $^{1}$, Edwin Musdi ${ }^{2}$ dan Ahmad Fauzi ${ }^{3}$ \\ 1 Mahasiswa Pascasarjana FMIPA, Universitas Negeri Padang \\ Padang, Sumatera Barat, Indonesia \\ rahmiati69@yahoo.com \\ 2,3 Staff Pengajar Pascasarjana FMIPA, Universitas Negeri Padang \\ Padang, Sumatera Barat, Indonesia
}

\begin{abstract}
Abstrak
Salah satu tujuan pembelajaran matematika yang harus dikuasai siswa adalah kemampuan pemecahan masalah. Namun kenyataannya dilapangan siswa masih kesulitan dalam menyelesaikan masalah matematika, khususnya pada materi bangun ruang sisi datar. Penelitian ini bertujuan untuk mengembangkan perangkat pembelajaran matematika berbasis discovery learning yang valid, praktis dan efektif dalam meningkatkan kemampuan pemecahan masalah. Model pengembangan yang digunakan adalah model Plomp. Model ini dilakukan dalam 3 tahap. Pada tahap pertama adalah fase investigasi awal (preliminary research) dilakukan analisis kebutuhan, analisis kurikulum, analisis siswa dan analisis konsep. Pada tahap kedua adalah fase pengembangan atau pembuatan prototipe (development or prototyping phase) yang didesain sesuai dengan model discovery learning dilakukan evaluasi sendiri, validasi pakar/ahli, evaluasi satu-satu, evaluasi kelompok kecil. Pada tahap ketiga adalah fase penilaian (assessment phase) bertujuan untuk melihat keefektivan perangkat pembelajaran dengan melakukan uji lapangan kelompok besar di kelas VIII MTsN 1 Bukittinggi. Agar menghasilkan perangkat pembelajaran matematika berbasis discovery learning yang valid, praktis, dan efektif. Kata Kunci: Perangkat Pembelajaran, Discovery Learning, Model Plomp.
\end{abstract}

\begin{abstract}
One of the goals of learning mathematics that must be mastered by students is the ability problem-solving. But the reality in the field of students is still difficult in solving math problems, especially on the matter of building a flat side room. This study aims to develop a learning device based on discovery learning mathematics that is valid, practical and effective in improving problem-solving skills. The development model used is the Plomp model. This model is done in 3 stages. In the first phase is the preliminary research phase of needs analysis, curriculum analysis, student analysis and concept analysis. In the second phase is the development or prototyping phase which is designed according to the discovery learning model by self-evaluation, expert / expert validation, one-to-one evaluation, small group evaluation. In the third stage is the assessment phase aims to see the effectiveness of learning tools by conducting large group field test in grade VIII MTSN 1 Bukittinggi. In order to produce a valid, practical, and effective learning tool based on discovery learning mathematics.
\end{abstract}


Keyword: Learning Device, Discovery Learning, Model Plomp.

\section{Pendahuluan}

Pembelajaran sangat erat kaitannya dengan ilmu pengetahuan. Salah satu jenis ilmu pengetahuan yang penting dimiliki adalah matematika. Matematika merupakan salah satu mata pelajaran yang sangat berperan penting dalam keberhasilan program pendidikan, karena matematika bagian dari pendidikan akademis dan ilmu dasar bagi disiplin ilmu yang lain. Namun, masih banyak siswa yang kurang menyukai pelajaran matematika. Ini disebabkan karena siswa merasa kesulitan dalam menyelesaikan permasalahan matematika khususnya dalam menyelesaikan soal-soal, pemecahan masalah, dan mengubah soal kehidupan sehari-hari ke dalam model matematika. Salah satu penyebabnya karena siswa kurang memahami konsep materinya, sehingga salah satu tujuan pembelajaran matematika yang harus dikuasai siswa yaitu kemampuan pemecahan masalah menjadi tidak terpenuhi.

Berdasarkan observasi di lapangan yang dilakukan pada bulan Juli 2015, terlihat bahwa banyak siswa yang tidak terbiasa menyelesaikan soal ujian matematika yang secara khusus dirancang guru agar siswa menguasai tujuan pembelajaran matematika, khususnya kemampuan pemecahan masalah. Kemampuan pemecahan masalah akan meningkat jika peserta didik memahami konsep materi pembelajaran, oleh karena itu dibutuhkan pembelajaran yang membantu peserta didik menemukan sendiri konsep-konsep agar peserta didik menyelesaikan masalah matematis. Banyak hal yang mempengaruhi pelaksanaan pembelajaran matematika. Pelaksanaan pembelajaran tentunya berpedoman pada suatu perangkat pembelajaran yang harus dirancang terlebih dahulu oleh guru serta memanfaatkan suatu bahan ajar yang efektif untuk mencapai tujuan pembelajaran diantaranya mengembangkan RPP dan LKS yang dapat digunakan dalam pembelajaran.

RPP dan LKS yang dirancang menggunakan model pembelajaran discovery. Dalam pembelajaran discovery siswa tidak hanya dituntut agar menguasai materi pelajaran, akan tetapi bagaimana mereka dapat menggunakan potensi yang dimilikinya. Guru mempunyai peran aktif dalam menentukan permasalahan dan tahap-tahap pemecahannya. Dengan pembelajaran discovery ini siswa belajar lebih berorientasi pada bimbingan dan petunjuk dari guru hingga siswa dapat memahami konsep-konsep pelajaran.

Menurut Bell (1981:241) "discovery learning is a learning which occurs as a result of the learner manipulating, structuring and transforming information so that he or she find new information". Dengan kata lain, discovery learning merupakan suatu proses belajar yang 
mana konsep pembelajaran itu tidak langsung disajikan, tetapi siswa diminta untuk mendapatkan sendiri konsepnya sehingga siswa dapat menemukan konsep / informasi baru. Menurut Syah (2004:244) dalam Hosnan ada beberapa prosedur dalam mengaplikasikan discovery learning dalam pembelajaran yaitu:

a. Stimulation (stimulasi/pemberian rangsangan), pada tahap ini guru dapat memulai kegiatan PBM dengan mengajukan pertanyaan, anjuran membaca buku, dan aktivitas belajar lainnya yang mengarah pada persiapan pemecahan masalah.

b. Problem

statement (pernyataan/identifikasi masalah), pada tahap ini guru memberikan kesempatan siswa untuk mengidentifikasi dan menganalisa permasalahan yanng mereka hadapi. Teknik ini berguna dalam membangun pola pikir siswa agar mereka terbiasa untuk menemukan suatu masalah.

c. Data collection (pengumpulan data), pada tahap ini siswa belajar secara aktif untuk menemukan sesuatu yang berhubungan dengan permasalahan yang dihadapi, dengan demikian secara tidak sengaja siswa menghubungkan masalah dengan pengetahuan yang telah dimiliki.

d. Data processing (pengolahan data), pada tahap ini siswa mengolah data dan informasi yang telah diperoleh baik melalui wawancara, observasi, dan sebagainya, lalu ditafsirkan e. Verification (pembuktian), pada tahap ini melakukan pemeriksaan secara cermat untuk membuktian benar atau tidaknya hipotesis yang ditetapkan tadi dengan temuan alternatif, dihubungkan dengan hasil data processing.

f. Generalization (menarik kesimpulan/generalisasi), tahap penarikan kesimpulan.

Rumusan masalah dalam penelitian ini adalah: "Bagaimana karakteristik perangkat pembelajaran matematika berbasis discovery learning yang valid, praktis, dan efektif dalam meningkatkan kemampuan pemecahan masalah siswa kelas VIII SMP? “

Permendikbud Nomor 22 tahun 2016 (2016:6) menjelaskan bahwa Rencana Pelaksanaan Pembelajaran (RPP) adalah rencana kegiatan pembelajaran tatap muka untuk satu pertemuan atau lebih. Rencana Pelaksanaan Pembelajaran (RPP) merupakan realisasi dari pengalaman belajar siswa yang telah ditentukan pada silabus pembelajaran.

Menurut Prajitno (2003:7), "LKS adalah suatu sarana untuk menyampaikan konsep kepada siswa baik secara individual maupun kelompok kecil yang berisi petunjuk untuk melakukan berbagai kegiatan".

Indikator kemampuan pemecahan masalah yang digunakan dalam penelitian ini adalah sebagai berikut: (1) Memahami masalah yang meliputi: mengidentifikasi data yang diketahui, mengidentifikasi data yang ditanyakan, mengidentifikasi data 
yang ditanyakan. (2) Merencanakan penyelesaian atau memilih strategi. (3) Melaksanakan pehitungan atau menyelesaikan masalah. (4) Memeriksa kembali kebenaran hasil atau jawaban.

Pengembangan suatu produk dikatakan berkualitas apabila perangkat tersebut valid, praktis, dan efektif. Validitas perangkat pembelajaran secara metodologi harus memenuhi validitas isi dan validitas konstruk. Validitas isi artinya kesesuaian antara produk yang dihasilkan dengan silabus mata pelajaran, kesesuaian dengan isi kurikulum yang sedang berlaku, dan kesesuaian perangkat pembelajaran yang akan dikembangkan dengan pengalaman belajar siswa. Validitas konstruk yaitu kesesuaian antara produk yang dihasilkan dengan unsur pengembangan yang telah ditetapkan. Perangkat pembelajaran yang dikatakan praktis adalah jika guru dan siswa dapat menggunakan perangkat pembelajaran tersebut dengan mudah dalam proses pembelajaran. Efektivitas perangkat pembelajaran merupakan keterpakaian perangkat dalam mencapai tujuan pembelajaran yang diharapkan. Efektivitas suatu perangkat dilihat dari hasil tes akhir peserta didik setelah menggunakan perangkat pembelajaran yang dikembangkan.

\section{Metode}

Jenis penelitian adalah penelitian pengembangan (research and development). Perangkat pembelajaran yang dikembangkan dalam penelitian ini meliputi: Rencana Pelaksanaan Pembelajaran (RPP) dan Lembar Kegiatan Siswa (LKS) untuk bangun ruang sisi datar pada siswa kelas VIII SMP.

Model pengembangan yang digunakan adalah model Plomp. Model ini dikembangkan oleh Tjeerd Plomp. Model Plomp terdiri dari 3 tahap, yaitu fase investigasi awal (preliminary research), dengan melakukan analisis kebutuhan (untuk mengetahui masalah dasar yang dibutuhkan dalam pengembangan perangkat pembelajaran), analisis kurikulum, analisis konsep, dan analisis karateristik siswa (meliputi tingkat kognitif, usia, gaya belajar, dan motivasi belajar siswa, sehingga perangkat pembelajaran yang dihasilkan sesuai dengan karakteristik siswa.

Fase pengembangan atau pembuatan prototipe (development or prototyping phase), dilakukan perancangan perangkat pembelajaran matematika berbasis discovery learning pada materi bangun ruang sisi datar, kemudian dilakukan evaluasi sendiri (self evalution) oleh peneliti. Hasil analisis dan revisi selanjutnya diberikan kepada lima orang validator (experts review) untuk divalidasi. Hasil validasi perangkat pembelajaran kemudian direvisi dan setelah dikatakan valid maka dilakukan evaluasi perorangan (one-to-one). Evaluasi one-to-one dilaksanakan oleh tiga orang siswa dengan kemampuan tinggi, sedang dan rendah. Kemudian dilanjutkan dengan evaluasi kelompok kecil (small group) oleh enam orang peserta didik. Selanjutnya fase 
penilaian (assessment phase) diujikan cobakan terbatas di MTsN 1 Bukittinggi. Pada tahap ini dilakukan uji praktikalitas dan uji efektivitas.

\section{UCAPAN TERIMA KASIH}

Penulis mengucapkan terimakasih kepada Dr. Edwin Musdi, M.Pd dan Dr. Ahmad Fauzi, M.Si yang telah membimbing peneliti dalam menyelesaikan proposal tesis ini. Jurnal ini disusun berdasarkan proposal tesis yang ditulis oleh Rahmiati yang Berjudul " Pengembangan Perangkat Pembelajaran Matematika Berbasis Discovery Learning untuk Meningkatkan Kemampuan Pemecahan Masalah Siswa Kelas VIII SMP"

\section{Daftar Pustaka}

Bell, Federick H. 1981. Teaching and Learning Matematics. America: Publishing Company.

Hosnan. 2014. Pendekatan Saintifik Dan Kontekstual Dalam Pembelajaran Abad 21. Jakarta :Ghalia Indonesia.

Peraturan Menteri Pendidikan dan Kebudayaan Republik Indonesia Nomor 22 Tahun 2016 tentang Standar Proses Pendidikan Dasar dan Menengah. Jakarta: Kemendikbud.

Plomp, T dan N. Nieveen. 2013. Educational Design Research. Enshede: Netherlands InstituteFor Curriculum Development (SLO). 
This page is intentionally left blank 